Considering previous reactions, laboratory findings and results of the oral challenge test, we suggest that our patient meets the criteria for DIES by amoxicillin. We performed a comprehensive literature search and found three cases of DIES reported in children and one in an adult patient who developed a severe reaction with shock.

In our opinion, the clinical awareness on DIES and its potential severity should be improved and it is important to distinguish it from side effect of the drug.

\section{DRUG ALLERGY - 5- YEAR CASE SERIES}

Ana Rita Curval*, Beatriz Vieira, Juliana da Silva Cardoso, Maria José Dinis. Pediatrics Department, UAG da Mulher e da Criança, Centro Hospitalar Universitário de São João, Porto

\subsection{6/archdischild-2021-europaediatrics.143}

Drug allergy suspicion is a frequent reason for referral to allergology specialty in pediatric age. However, this suspicion is rarely confirmed, and the drug provocation test (DPT) is fundamental for the diagnosis. Thus, with this work we intend to characterize the pediatric population with suspected drug allergy referred to the Pediatric Allergology consultation.

Retrospective analysis of the clinical processes of children ( $<18$ years) with suspected drug allergy followed in the Pediatric Allergology consultation between 2015 and 2019. Demographic data, history of allergic disease, clinical manifestations, performed therapy and guidance were evaluated.

The sample included 118 children, 54\% female, with an average age of 5 years and 2 months (range from 5 months to 18 years). 38 children had a personal history of atopy, including recurrent wheezing and atopic dermatitis, and 29 children had an history of allergy in first-degree relatives. The reactions that increased the suspicion of drug allergy were mostly mucocutaneous $(\mathrm{n}=$

107) and gastrointestinal $(n=11) .49$ children were observed in the emergency service for this reason. They were medicated with isolated antihistamine $(n=33)$, antihistamine + corticosteroid $(\mathrm{n}=11)$ and antihistamine + corticosteroid + adrenaline $(n=5)$. IgEs were specifically quantified in 106 cases (for Amoxicillin, Ampicilloil and Penicilloic G and V), with a positive result in only 2. DPT were performed for antibiotics (amoxicillin $(\mathrm{n}=53)$, amoxicillin/clavulanic acid $(\mathrm{n}=$ 49), penicillin $(n=4)$, cefuroxime $(n=2)$, azithromycin $(n=$ $1)$, cefixime $(n=1))$, paracetamol $(n=5)$ and ibuprofen $(n=1)$, with a positive result in 4 children. Verified reactions were mucocutaneous and gastrointestinal, without cases of anaphylaxis.

Drug allergy in children is an important topic of debate, as overdiagnosis is quite common, hindering the clinical approach and leading to the eviction of several first-line therapies. Thus, we want to alert to the importance of an early referral in order to obtain a correct and clear diagnosis.

\section{ANALYSIS OF THE PREVALENCE OF ALLERGIC DISEASES IN ADOLESCENTS IN THE RUSSIAN FEDERATION}

Elena Kaitukova*, EA Vishneva, EV Komarova, LS Namazova-Baranova, AA Alekseeva. Central Clinical Hospital of the Russian Academy of Sciences, Moscow

10.1136/archdischild-2021-europaediatrics. 144
To assess prevalence of allergic diseases among schoolchildren in the Russian Federation (RF) in the age groups of 11 and 15 years.

The data obtained during the screening of schoolchildren (which included surveys of parents and school doctors with specially designed questionnaires, an allergist's examination, spirometry) -the project of the RF and the WHO European Office for the development of the school medicine network. 2114 schoolchildren were examined in the following federal districts: Central Federal District - CFD, Southern Federal District - SFD, North-Western Federal District - NWFD, Volga Federal District - VFD, Ural Federal District - UFD, Siberian Federal District - SibFD, Far Eastern Federal District - FEFD.

Analysis of the results suggests that the smallest number of children with manifestations of allergic diseases was noted in the SibFD $\mathrm{n}=81(24 \%)$, and the largest in the UFD $\mathrm{n}=$ 107 (36\%); by districts: in the CFD $\mathrm{n}=83$ (31\%), NWFD $\mathrm{n}$ $=87(32 \%)$, FEFD $\mathrm{n}=91(30 \%)$, SFD $\mathrm{n}=100(30 \%)$, VFD $\mathrm{n}=102(32 \%)$.

At the same time, the average of bronchial asthma (BA) was $2 \%$, seasonal allergic rhinitis (SAR) $-8 \%$, allergic rhinitis (AR) $-8 \%$, atopic dermatitis

- 2\%, food allergy (FA) - 13\%, drug allergy (DA) - 3\%. Regional peculiarities were revealed: the prevalence of BA varied from $1-1.5 \%$ in the NWFD, VFD, FEFD, SFD to $6 \%$ in the UFD. The prevalence of seasonal AR ranged from $2 \%$ in the NWFD and $3 \%$ in the FEFD to $12 \%$ in the UFD and $16 \%$ in the North Caucasus Federal District. Perennial AR accounted for from $3 \%$ in the CFD to $11 \%$ in the UFO and $16 \%$ of the FEFD. The highest incidence of food allergy was registered in the Volga Federal District and CFD, 17\% and $16 \%$, respectively, and only $10 \%$ in the SFD and in the SibFD. AD was diagnosed in equal shares in the CFD and NWFD (3\%), in the UFD - $2 \%$, in the SFD, VFD, SFD and FEFD - $1 \%$.

The true prevalence of allergic diseases among schoolchildren of the Russian Federation is significantly higher than data of official statistics but differs by regional peculiarities. The true prevalence has appeared to be in

2-20 times above the data of official statistics: data of official statistics for BA in 2015 amounted to 2,7\%, for AR $0,9 \%$.

\section{NOVEL MARKERS FOR ATOPIC DERMATITIS PHENOTYPES AT CHILDREN}

Volodymyr Dytiatkovskyi, Olexandr Abaturov. S/ 'Dnipropetrovsk Medical Academy of the MH of Ukraine'

10.1136/archdischild-2021-europaediatrics. 145

To study the associations of onset and progression risks of atopic dermatitis (AD) phenotypes as a mono-nosology or combined with seasonal allergic rhino-conjunctivitis (SARC) and/or perennial allergic rhinitis

(PAR) at children with serum concentrations of immunoglobulin (IgE) total, cutaneous T-cell attracting chemokine (CTACK) and thymus and activation regulated chemokine (TARC).

We recruited 39 patients into the main group suffering from different $\mathrm{AD}$ phenotypes (as mono-nosology and combined with SARC and/or PAR) and 47 patients - into the 
control group (non-atopics suffering from functional dyspepsia, chronic gastritis, functional biliary disorders).

Atopy at all the main group patients was confirmed by the elevated serum total IgE detected by the electro-chemiluminescence quantitative determination method. All the patients of the main and control groups had undergone CTACK and TARC detection using the enzyme-linked immunosorbent quantitative determination method.

Association between IgE total, CTACK, TARC and AD phenotypes was determined by the Spearman rank-order correlation (R). For detecting the risks associated with onset of $\mathrm{AD}$ different phenotypes we had determined odds ratio (OR) with $95 \%$ confidence interval (CI) by application of ROC-analysis.

All the data was validated by $p$-value $(p<0.05)$.

There is a significant association between serum total $\operatorname{IgE}$ and CTACK with $\mathrm{AD}$ as mono-nosology - $\mathrm{R}=0.385$ and $\mathrm{R}=0.341 \quad(\mathrm{p}<0.01)$ and with $\mathrm{AD}$ combined with SARC and/or PAR $-\mathrm{R}=0.718$ and $\mathrm{R}=0.397(\mathrm{p}<0.01)$. Risk of onset of $\mathrm{AD}$ as mono-nosology is significantly associated with serum $\mathrm{IgE}>173 \mathrm{IU} / \mathrm{ml}-\mathrm{OR}=$

$8.98[95 \%$ CI 2.53, 31.86], p $<0.001$ and CTACK $\geq$ $3658,5 \mathrm{pg} / \mathrm{ml}-\mathrm{OR}=5.64[95 \%$ CI 1.56, 20.32, $] \mathrm{p}<0.01$. Risk of AD combined with SARC and/or PAR onset is significantly associated with serum CTACK $\geq 4308.8 \mathrm{pg} / \mathrm{ml}-\mathrm{OR}$ $=7.40$ [95\% CI 2.30, 23.76], $\mathrm{p}<0.001$. Risk of progression of $\mathrm{AD}$ as mono-nosology into $\mathrm{AD}$ combined with SARC and/ or PAR is significantly associated with total serum $\operatorname{IgE} \geq$ $1000 \mathrm{IU} / \mathrm{ml}-\mathrm{OR}=16,0$ [95\% CI 2.68, 95.44], $\mathrm{p}<0.001$.

Serum IgE total and CTACK are significantly associated with the studied AD phenotypes.

Risk of $\mathrm{AD}$ as a mono-nosology onset is significantly associated with serum total $\mathrm{IgE} \geq 173 \mathrm{IU} / \mathrm{ml}$ and CTACK $\geq$ $3658,5 \mathrm{pg} / \mathrm{ml}$, AD combined with SARC and/or PAR - serum CTACK $\geq 4308.8 \mathrm{pg} / \mathrm{ml}$.

Risk of progression of $\mathrm{AD}$ as mono-nosology into $\mathrm{AD}$ combined with SARC/and or PAR is significantly associated with serum total $\mathrm{IgE} \geq 1000 \mathrm{IU} / \mathrm{ml}$.

There is no significant association between serum TARC and the risk of $\mathrm{AD}$ phenotypes onset.

\section{THE LONG-TERM MONITORING AND ANALYSIS OF OUTCOMES OF DIFFERENT APPROACHES TO THE MANAGEMENT OF CHRONIC SPONTANEOUS IN ADOLESCENTS}

Vera Kalugina*, L Namazova-Baranova, E Vishneva, P Arimova, L Aslamazyan. 'Research Institute of Pediatrics and Child Health Care Central Clinical Hospital of Russian Academy of Science, Moscow, Russia; ${ }^{2}$ Pirogov Russian National Research Medical University (RNRMU), Moscow, Russia

\subsection{6/archdischild-2021-europaediatrics. 146}

Second-generation of $\mathrm{H} 1$-antihistamines $(\mathrm{H} 1-\mathrm{AH})$ is the main therapy for the chronic spontaneous urticaria (CSU). Omalisumab (Omab) is the only biological, approved for the severe $\mathrm{H} 1-\mathrm{AH}$ resistant CSU in adolescents over

12 years.

Aim: to evaluate different approaches to severe CSU therapy in adolescents and assess achieving of disease control in 3 y period.

Methods The long-term prospective observation study of 34 children with severe CSU (55\% boys, average age 13 y o $(\min 3 ; \max 17,0)$, the duration of disease $-33 \operatorname{mo}(\min 3$; $\max 144$ ); UAS7 - 18 points ( $\min 16$; $\max 24,0$ ) was conducted. All patients received $\mathrm{H} 1-\mathrm{AH}$ for minimum 3 mo.

Patients were randomized in 2 groups. 17 patients of the 1st group were added with Omab to therapy: 55,6\% girls, average age -15 y $(\min 12,0 ; \max 17,0)$; disease duration was 45,2 mo $(\min 3,0 ; \max 144,0)$, the average total $\operatorname{IgE}$ level - 348,2 IU/mL ( $\min 0,8 ; \max 2041,0)$; the average UAS7 at debut -

17,2 points $(\min 16 ; \max 24)$. The course of Omab therapy was $6 \mathrm{mo}, 300 \mathrm{mg} / \mathrm{mo}$ subcutaneously.

17 patients of the 2 nd group maintained alone $\mathrm{H} 1-\mathrm{AH}$ therapy: $64,7 \%$ boys, average age $-10,8$ y (min 3,0; $\max$ $15,0)$; disease duration was $20,5(\min 3 ; \max 72) \operatorname{mo}$, the average total $\mathrm{IgE}$ level $-182 \mathrm{IU} / \mathrm{mL}(\min 20$; $\max 1050)$;

UAS7 at debut - 18 ( $\min 16$; $\max 28)$ points.

The efficacy of therapy assessed by urticaria activity score for the 7 days (UAS7).

Results in the 1 st group of patients in 6 mo of Omab therapy UAS7 was $1,6(\min 0 ; \max 20)$ points, $\mathrm{p}<0,05$. After 3 $\mathrm{y}$ of the course Omab therapy UAS7 was 4,5 points, $\mathrm{p}<0,05$.

In the 2 nd group of patients, who received alone $\mathrm{H} 1-\mathrm{AH}$, in 6 mo UAS7 remained at the same level -18 points $(\mathrm{p}<$ $0,05)$. The average UAS7 in $3 \mathrm{y}$ was 12 ( $\min 0 ; \max 26)$ points $(\mathrm{p}<0,05)$.

Thus, in patients receiving Omab UAS7 significantly decreased after 6 mo.

The UAS7 level in the Omab group indicates a greater proportion of children who have achieved disease control. The proportion of children, who have achieved remission during 3 y $(\mathrm{UAS} 7=0)$ : in Omab group $52,9 \%$, in $\mathrm{H} 1-\mathrm{AH}-29,4 \%$ $(\mathrm{p}=0,163)$.

Conclusion Our results indicate the efficacy of Omab in adolescents with

CSU: rapid relief of urticaria symptoms and a greater proportion of adolescents who have achieved disease control, compared with therapy alone H1-AH.

\section{STEVENS-JOHNSON SYNDROME}

Nedim Strukar*, Verica Mišanović, Adisa Čengić, Aida Karačić, Alma Mujić, Emina Ribić. Department of Pediatrics, Travnik County Hospital, Travnik, Bosnia and Herzegovina

10.1136/archdischild-2021-europaediatrics. 147

Stevens-Johnson syndrome (SJS) is a severe mucocutaneous reaction characterized by extensive necrosis and separation of the epidermis. The mucous membranes are affected in over $90 \%$ of patients, usually in two or more different sites. The incidence ranges from 2 to 7 cases per million people per year. Medication use is a leading trigger of Stevens-Johnson syndrome in both adults and children, followed by Mycoplasma pneumoniae infection. The disease begins with flu-like symptoms and fever, followed by the onset of mucocutaneous and skin changes. The diagnosis is based on clinical and histological findings in a patient with a history of previous medication exposure or febrile illness.

A 10-year-old boy presented with fever, cough, and dyspnoea. He was examined ten days before the admission and prescribed with antibiotic.

Physical examination shows dehydration and light dyspnoea, along with mild diffuse bulbar injection of both eyes, and moderate oedema and hyperaemia of the tonsils and pharyngeal mucosa. There was no skin rash. Auscultation of lungs 